2018

\title{
Investigating Three Approaches of Using Personality to Predict Competency-Based Performance
}

\author{
Blaine Gaddis \\ Hogan Assessment Systems \\ Brandon Ferrell \\ Hogan Assessment Systems
}

Follow this and additional works at: https://scholarworks.bgsu.edu/pad

Part of the Human Resources Management Commons, Industrial and Organizational Psychology Commons, and the Other Psychology Commons

How does access to this work benefit you? Let us know!

\section{Recommended Citation}

Gaddis, Blaine and Ferrell, Brandon (2018) "Investigating Three Approaches of Using Personality to Predict Competency-Based Performance," Personnel Assessment and Decisions: Number 4 : Iss. 1 , Article 3.

DOI: https://doi.org/10.25035/pad.2018.003

Available at: https://scholarworks.bgsu.edu/pad/vol4/iss1/3

This Main Article is brought to you for free and open access by the Journals at ScholarWorks@BGSU. It has been accepted for inclusion in Personnel Assessment and Decisions by an authorized editor of ScholarWorks@BGSU. 


\title{
Investigating Three Approaches of Using Personality to Predict Competency-Based Performance
}

\author{
Blaine Gaddis ${ }^{1}$ and Brandon Ferrell ${ }^{2}$
}

1. Independent Contractor

2. Hogan Assessment Systems

ABSTRACT

\begin{abstract}
Organizations often use competencies to drive human capital initiatives such as recruitment, selection, training, and promotion. To serve such organizations, practitioners now offer various competency-based research solutions incorporating personality assessments to predict these competencies. Each approach begins by mapping competencies from an organization's model to scientific models backed by synthetic and content validity evidence to align personality dimensions with each competency. This helps determine which personality dimensions drive performance for each competency. In this paper, we compare scale-based profiles, subscale-based algorithms, and scale-based algorithms to investigate the consistency of scores across methods and how effective each method is in predicting

competency-based performance.
\end{abstract}

\section{KEYWORDS \\ competencies, personality, scoring performance}

Organizations are increasingly using competencies to evaluate personnel for hiring, promotion, training, and other purposes. Although businesses continue to use job analysis to describe work activities, many have also adopted custom competency models to identify common performance themes across jobs, work groups, and divisions (Schippmann et al., 2000). Competencies provide a common framework that practitioners can use to drive a variety of HRM applications (e.g., selection, development, succession planning, strategy and change initiatives; Schippmann, 2010).

Traditional job analysis and more contemporary competency modeling practices both represent efforts to classify job requirements and use that information to drive HRM applications, so why would competency modeling be better suited for applications like selection, employee development, succession planning, and strategy and change initiatives? In short, because competency modeling is more naturally suited for organizational contexts than its more academic counterpart in job analysis. Explaining the differences between job analysis and competency modeling, Sanchez and Levine (2009) distinguish between these activities along six dimensions. In terms of the purpose of the activity, job analysis aims to describe behavior, whereas competency modeling seeks to influence it. Job analysis tends to view jobs as external objects to be described, whereas competency-based methods view jobs as roles to be enacted. Job analysis maintains focus on one job at a time, but competency modeling focuses on the organization as a whole. Job analyses also tend to be focused on the past, whereas competency models tend to be more future facing. In describing performance levels, job analysis methods outline typical performance, but competency modeling efforts identify maximum performance. Finally, job analysis methods often use a latent trait approach to measurement, whereas competency modeling initiatives are based in clinical or expert judgment. These key differences between traditional job analysis and competency modeling illustrate why competency modeling has largely replaced job analysis by organizations seeking to influence employee behavior toward accomplishing key strategic goals.

In outlining some best practices for competency modeling, Campion et al. (2011) provide 10 key differences between job analysis and competency modeling. Relative to job analysis, the authors find that competency modeling

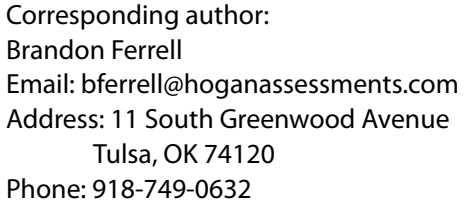

This article describes research conducted using measures and data provided by Hogan Assessment Systems. Brandon Ferrell is a paid employee of Hogan. Datasets included in this research are considered proprietary. 
(a) gets more attention from organizational executives, (b) better distinguishes top performers from average or poor performers, (c) describes progressions in attributes across job levels, (d) links directly to business objectives and strategies, (e) garners more buy-in through top-down development, (f) considers changing and future job requirements, (g) facilitates ease of use through the use of organizationally specific language, (h) applies the same model across multiple functions or job families, (i) better aligns HR systems, and (j) provides better organizational return on investment when applied across broad organizational change efforts. In these ways, competency modeling provides an opportunity to move job analysis from its academic roots into mainstream organizational applications. As such, Campion et al. (2011, pg. 226) characterize competency modeling as the "Trojan horse" for job analysis. Others have made similar observations, arguing that the inherent adaptability of competency modeling allows it to accommodate complex, changeable positions and the complex and collaborative problem-solving activities required in those positions (Sliter, 2015).

An additional benefit of competency modeling is the increased transparency and access to information relative to job analysis information. For example, Rodriguez, Patel, Bright, Gregory, and Gowing (2002) described the adoption of a competency framework in the Office of Personnel Management (OPM), forming a foundation for applicant selection, employee development, performance management, and organizational strategic planning initiatives among others. Using this competency framework provided a common method for describing a wide range of jobs the same way, thereby eliminating inconsistencies and waste in time and resource expenditures. Moreover, including this competency model in automated systems at OPM ensured access to a shared frame of reference for all employees, HR professionals, and managers.

Reflecting these shifts from job analysis to competency modeling, practitioners have observed a rapid increase in the number of requests from organizations that want to link assessments to their competency-based frameworks. To meet this demand, professionals have developed a variety of competency-based solutions that align scales and/or subscales from various assessments to organizational competency models.

Bartram (2005) demonstrated the value of such an approach in his research on the "Great Eight" competency framework. In his work, the author used data from various personality scales from the Occupational Personality Questionnaire (OPQ; SHL, 2006) as predictor measures across 29 validation studies $(\mathrm{N}=4,861$; $\mathrm{Mdn} \mathrm{n}=125$ per study) from Belgium, Egypt, France, Germany, Korea, the Netherlands, South Africa, Turkey, the UK, and the U.S. These studies included data from across a number of industries and jobs, primarily managerial positions. The author used supervisory performance ratings on competency instruments as criterion outcomes, aligning each competency with those from the Great Eight framework. After mapping conceptually aligned personality scales onto the Great Eight competencies and standardizing both predictor and criterion data, the author ran individual study correlations from each study and corrected for criterion unreliability and predictor range restriction. After making these adjustments, the author ran meta-analyses using procedures described by Hunter and Schmidt (2004) to determine general predictorcriterion relationships between personality-based predictors and managerial performance ratings for the Great Eight competencies. His results indicated that substantial predictive relationships exist between matched pairs of personality-based predictors and managerial performance ratings for the Great Eight competencies.

As with the previous observations about job analysis and competency modeling in general, both similarities and key differences exist between personality-based job analysis and the use of personality assessment in competency modeling. Foster, Gaddis, and Hogan (2012) outlined how to conduct personality-based job analysis. Despite the fact that incumbents and supervisors typically describe effective job performance in terms of personality characteristics, most structured job analysis procedures do not capture them (Guion, 1992). Other researchers (Raymark, Schmit, \& Guion, 1997) have made similar observations that if a job analysis method emphasizes only cognitive or psychomotor constructs, it is likely to conclude that only cognitive or psychomotor predictors are relevant to the job. More recently, however, Highhouse et al. (2016) developed a public-domain personality item bank that researchers can use to assess job-related traits related to important performance outcomes. As this more recent research demonstrates, personality-based job analysis ratings predict the criterionrelated validity of personality assessment scores (Cucina, Vasilopoulos, \& Sehgal, 2005). Reflecting job analytic techniques that do take personality into account, Foster et al. (2012) describe how to survey subject matter experts (SMEs) about the personality-related characteristics that are most beneficial (or detrimental) for performance in a job.

However, personality-based job analysis information still applies most directly to specific jobs, may not link directly to business objectives, and develops through bottomup methods that may limit buy-in from key organizational stakeholders. As such, using personality assessment in competency modeling efforts may prove more beneficial to organizations than personality-based job analysis. Besides the advantages previously noted by Campion et al. (2011), competency modeling that incorporates personality assessment data can account for interactionist models of job performance. Tett and Burnett (2003) provide one such model built on an interactionist principle of trait activation (Tett \& Guterman, 2000). The authors describe five situational fea- 
tures (i.e., job demands, distracters, constraints, releasers, and facilitators) that may moderate the relationships among personality traits, work behavior, and job performance. Because these situational features operate at social and organizational levels, they are better captured by incorporating personality information into broad competency modeling efforts rather than more specific job analysis initiatives.

Typically, competency-based research solutions start with mapping each competency in an organization's model to a matching competency from a scientific or academic competency model. Those competency mappings allow researchers to identify scales and/or subscales that are empirically or theoretically related to an organization's competency and use those scales or subscales to predict performance of that competency. With predictive competency mappings in place and considering other factors such as an organization's needs, practitioners typically use one of three different approaches to align personality assessment scales or subscales to competencies from organizational models:

- Scale-based profiles: This approach uses synthetic and content validity evidence to identify scales that predict each competency and results in recommended cutoff scores where individuals must score in certain ranges on each scale to create a traditional fit profile for each competency. In these fit profiles, individuals' scores on predictive personality scales place them into a level of fit (i.e., low, moderate, or high fit) with the competency outcome based on the extent of alignment between their personality and the associated outcome.

- Subscale-based algorithms: This approach also relies on synthetic and content validity evidence but uses personality subscales that predict each competency. Combining these subscales, researchers can create mathematical algorithms to predict performance of each competency.

- Scale-based algorithms: This approach is similar to subscale-based algorithms but uses normative scores on personality scales to predict performance of each competency. By combining the normative scores across those scales, researchers can create mathematical algorithms to predict performance of each competency.

Due to the prevalence of these three research approaches to predicting competency-based performance, the intent of our research is to investigate and compare the consistency of scoring and predictive validities across scalebased profiles, subscale-based algorithms, and scale-based algorithms. Because practitioners offer multiple research options for delivering competency-based solutions, a logical question concerns how similar scores are expected to be across these solutions. For example, if a person earns a high innovation score derived from a scale-based profile, how likely is it that he/she will also earn a high score for innovation derived from a subscale- or scale-based algorithm?
With these methods in mind, we offer the following hypotheses:

Hypothesis 1: Due to the consistency of scoring methods and construct levels, competency scores will be most consistent between subscale- and scale-based competency algorithms, followed by scale-based profiles and scale-based algorithms, and least consistent between scale-based profiles and subscale-based algorithms.

Hypothesis 2: Due to scoring methods and the inclusion of the most predictive constructs, subscale-based algorithms will best predict competency-based performance, followed by scale-based algorithms, and finally scale-based profiles.

\section{METHOD}

\section{Assessments}

To address our hypotheses, we used a large matched set of data from two personality assessments to score each competency using the scale-based profiles, subscale-based algorithms, and scale-based algorithms described below.

The Hogan Personality Inventory (HPI; R. Hogan \& Hogan, 2007) is an extensively validated measure examining "bright-side" personality and was the first such inventory specifically developed for occupational contexts with working adults. It contains seven scales that align with the five-factor model (FFM; Digman, 1990; Goldberg, 1992; John, 1990; McCrae \& Costa, 1987) of personality. The HPI reflects a person's normal, day-to-day behavior and is backed by a global archive of evidence confirming its validity for predicting individual, leadership, and team performance.

The Hogan Development Survey (HDS; R. Hogan \& Hogan, 2009) is also extensively validated but measures the "dark side" of personality, or a person's behavior under stress and other conditions that challenge self-regulation. These characteristics reflect negative tendencies that may inhibit a person's performance or derail their success. Like the HPI, the HDS is intended for use in normal populations of working adults and supported by a global archive of research supporting its validity in predicting workplace outcomes. The HDS contains 11 scales aligned with Horney's (1950) flawed interpersonal strategies of moving away from people, moving against people, and moving toward people in response to stress.

Table 1 presents the names, definitions, and sample items for each of the primary scales included in both the HPI and the HDS.

\section{Competency Measures}

Scale-based profiles. Creating scale-based profiles starts with mapping each competency from an organiza- 
TABLE 1.

Predictor Instruments, Scale Names, Definitions, and Sample Items

\begin{tabular}{|c|c|c|}
\hline Instrument and scale & Measures & Sample item \\
\hline HPI Adjustment & $\begin{array}{l}\text { Confidence, self-esteem, and } \\
\text { composure under pressure }\end{array}$ & $\begin{array}{l}\text { My coworkers think I am a calm } \\
\text { person. }\end{array}$ \\
\hline HPI Ambition & $\begin{array}{l}\text { Initiative, competitiveness, and desire } \\
\text { for leadership roles }\end{array}$ & I always play to win. \\
\hline HPI Sociability & $\begin{array}{l}\text { Extraversion, gregariousness, and } \\
\text { need for social interaction }\end{array}$ & I often go to parties in my free time. \\
\hline HPI Interpersonal Sensitivity & $\begin{array}{l}\text { Tact, perceptiveness, and ability to } \\
\text { maintain relationships }\end{array}$ & I am sensitive to others' feelings. \\
\hline HPI Prudence & $\begin{array}{l}\text { Self-discipline, responsibility, and } \\
\text { thoroughness }\end{array}$ & I do the best I can in everything I do. \\
\hline HPI Inquisitive & $\begin{array}{l}\text { Imagination, curiosity, and creative } \\
\text { potential }\end{array}$ & I ask other people a lot of questions. \\
\hline HPI Learning Approach & $\begin{array}{l}\text { Achievement orientation, valuing } \\
\text { education }\end{array}$ & $\begin{array}{l}\text { Doing well in school was always } \\
\text { important to me. }\end{array}$ \\
\hline HDS Excitable & $\begin{array}{l}\text { Moodiness, being hard to please, and } \\
\text { emotional volatility }\end{array}$ & $\begin{array}{l}\text { I frequently argue with my family and } \\
\text { friends. }\end{array}$ \\
\hline HDS Skeptical & $\begin{array}{l}\text { Suspiciousness, being sensitive to } \\
\text { criticism, and expecting betrayal }\end{array}$ & You can't trust anyone but yourself. \\
\hline HDS Cautious & $\begin{array}{l}\text { Risk aversion, being reluctant to } \\
\text { change, and slow to make decisions }\end{array}$ & $\begin{array}{l}\text { I worry about what the future might } \\
\text { bring. }\end{array}$ \\
\hline HDS Reserved & $\begin{array}{l}\text { Aloofness, being uncommunicative, } \\
\text { and indifferent to others' feelings }\end{array}$ & $\begin{array}{l}\text { Other people's problems don't } \\
\text { concern me. }\end{array}$ \\
\hline HDS Leisurely & $\begin{array}{l}\text { Private resentment, irritation, } \\
\text { stubbornness, and being uncooperative }\end{array}$ & $\begin{array}{l}\text { It doesn't hurt others at work to wait } \\
\text { on me. }\end{array}$ \\
\hline HDS Bold & $\begin{array}{l}\text { Arrogance, entitlement, and being } \\
\text { overly self-confident }\end{array}$ & $\begin{array}{l}\text { I insist that others treat me with the } \\
\text { proper respect. }\end{array}$ \\
\hline HDS Mischievous & $\begin{array}{l}\text { Excitement-seeking, risky behavior, } \\
\text { and being charming }\end{array}$ & $\begin{array}{l}\text { I have a reputation for being a risk- } \\
\text { taker. }\end{array}$ \\
\hline HDS Colorful & $\begin{array}{l}\text { Attention-seeking, being overly } \\
\text { dramatic, and interruptive }\end{array}$ & $\begin{array}{l}\text { I enjoy performing in front of an } \\
\text { audience. }\end{array}$ \\
\hline HDS Imaginative & $\begin{array}{l}\text { Unusual or eccentric patterns of } \\
\text { thinking and acting, odd creativity }\end{array}$ & $\begin{array}{l}\text { People think I am something of an } \\
\text { unusual character. }\end{array}$ \\
\hline HDS Diligent & $\begin{array}{l}\text { Meticulousness, precision, being hard } \\
\text { to please, and micromanaging }\end{array}$ & $\begin{array}{l}\text { It bothers me when others don't } \\
\text { proofread their work. }\end{array}$ \\
\hline HDS Dutiful & $\begin{array}{l}\text { Reluctance to act independently or } \\
\text { go against popular opinion, and being } \\
\text { eager to please }\end{array}$ & $\begin{array}{l}\text { It is smart to tell your boss what he/ } \\
\text { she wants to hear. }\end{array}$ \\
\hline
\end{tabular}


tion's model to one from a scientific or academic model, then identifying assessment scales with empirical and/or theoretical linkages to the competency from the scientific model. Using those scales, researchers can determine what scoring levels for those scales are associated with lower or higher competency-based performance, then use that information to set cutoff scores designed to classify individuals into various levels of fit (i.e., low, moderate, or high fit) with the competency based on the alignment between their scale scores and successful performance. In Tables 2 through 5, we present scale-based profiles for a sampling of intrapersonal, interpersonal, technical, and leadership competencies (Warrenfeltz, 1995). Each profile uses predictive scales from the HPI and HDS; normative cutoff scores; and low, moderate, and high levels of fit.

In terms of benefits, scale-based profiles are the most intuitive competency-based research solution, as they categorize individuals into low, moderate, or high fit categories based on how well their assessment scores align with successful demonstration of each competency. These solutions can also use any number of predictive assessment scales. Finally, because an individual's scores on multiple assessment scales determine their degree of fit with the profile, individuals can also gain valuable information about where they would benefit from feedback and coaching based on their scores that are lower or higher than those set in the profile.

However, the ease of interpretation gained by using low, moderate, and high categorical levels of fit with a profile may be offset by some loss of predictive validity due to the inclusion of both predictive and unpredictive subscales under a scale. In addition, scale-based profiles are often inflexible and noncompensatory, in that individuals cannot make up for one scale score that falls outside desired ranges by having other scale scores that fall within desired ranges.

Subscale-based algorithms. To address the most significant limitations associated with scale-based profiles (i.e., predictive validity, inflexibility), practitioners may also offer subscale-based algorithms. This approach also begins with mapping an organization's competencies to those from a scientific or academic competency model. However, instead of identifying which scales are empirically related to each competency, researchers can use synthetic validation evidence to identify the most predictive subscales for each competency. Using those subscales, they then create a mathematical algorithm to predict performance for each competency. Because subscales often include different numbers of items, researchers can unit weight subscale scores evenly or explore a number of differential weighting solutions based on the strength of prediction shown by each subscale.

Below, we present subscale-based algorithms for the same intrapersonal, interpersonal, technical, and leadership competencies presented in Tables 2 through 5. For consistency with the scale-based profiles previously described, each algorithm uses a combination of predictive subscales from the HPI and scales from the HDS.

- Achievement Orientation $=((($ Trusting $/ 3)-($ Curiosity/3) $+($ Not Spontaneous/4) $+($ No Guilt/6) + (Competitive/5) $+($ Leadership/6) $+($ Generates Ideas/5 $)+($ Identity/3) $-($ Dutiful/14) $-($ Skeptical/14 $)+3) / 10) * 50$

- Building Relationships $=((($ Empathy $/ 5)+($ Even Tempered/5) $+($ Likes Parties/5) $-($ Exhibitionistic/5 $)+($ Caring/4 $)+($ Virtuous/5) $-($ Leisurely/14) +2$) / 7) * 50$

- Innovation $=((($ Trusting/3) $)+($ Leadership/6) $)+($ Not Anxious/4 $)+($ Avoids Trouble $/ 5)+($ Generates Ideas $/ 5)+$ $($ Moralistic/5) $+($ Curiosity/3) $+($ Imaginative/14 $)-($ Cautious/14) - (Skeptical/14) +2)/10)* 50

- Strategic Planning $=((($ Trusting/3) $)+($ Competitive/5) $+($ Self Confidence/3) $+($ Experience Seeking/6) $-($ Culture/4) - (Diligent/14) - (Skeptical/14) - (Cautious/14) +4)/ $8) * 50$

Subscale-based algorithms can have high predictive validity due to the inclusion of only the most predictive subscales for each competency. Unlike scale-based profiles, this approach is also more flexible and compensatory in that individuals can make up for a deficient score on one subscale with a better score on other subscales included in the algorithm. Finally, this approach is customizable in that it can include a mix of subscales optimally weighted to maximize either interpretability of scores or prediction of performance.

However, the use of continuous algorithm scores instead of categorical low, moderate, or high fit levels can make subscale-based algorithms more difficult to interpret and less informative than scale-based profiles in terms of needed feedback and coaching efforts. Moreover, using raw scores in algorithms is not as directly interpretable as using interpretive scores in scale-based profiles.

Scale-based algorithms. To retain the benefits (i.e., predictive validity, flexibility) and address limitations (i.e., interpretation, mixing scales with subscales) of subscalebased algorithms, researchers may also use scale-based algorithms to predict competency-based performance. Like the scale-based profile approach, this solution begins with mapping competencies from an organization's model to those from a scientific or academic competency model and identifying personality dimensions with empirical and/or theoretical linkages to each competency. However, instead of building profiles, researchers create mathematical algorithms for each competency. Like scale-based profiles, scale-based algorithms can also use interpretive scores instead of raw scores, which unit weights the scales included in each algorithm and facilitates interpretation. Below, we present scale-based algorithms for the same intrapersonal, interpersonal, technical, and leadership competencies refer- 
TABLE 2.

Scale-Based Profile for Achievement Orientation (Intrapersonal Competency)

\begin{tabular}{|l|c|c|c|}
\hline Scale & Low fit & Moderate fit & High fit \\
\hline Ambition & & $\geq 46$ & $\geq 58$ \\
\hline Prudence & & $\geq 14$ & $\leq 14$ \\
\cline { 1 - 1 } Excitable & \multirow{3}{*}{$\begin{array}{c}\text { Fails to Satisfy } \\
\text { Moderate Fit } \\
\text { Minimum Scores }\end{array}$} & $\leq 90$ & $\leq 85$ \\
\cline { 4 - 4 } Dutiful & & $\leq 85$ & $\leq 73$ \\
\hline Leisurely & & & $\leq 88$ \\
\hline Skeptical & & & $\leq 87$ \\
\hline Imaginative & & & $\leq 75$ \\
\hline
\end{tabular}

Note. All cutoff scores reflect normative percentile ranks.

TABLE 3.

Scale-Based Profile for Building Relationships (Interpersonal Competency)

\begin{tabular}{|c|c|c|c|}
\hline Scale & Low fit & Moderate fit & High fit \\
\hline Interpersonal Sensitivity & \multirow{6}{*}{$\begin{array}{l}\text { Fails to Satisfy } \\
\text { Moderate Fit } \\
\text { Minimum Scores }\end{array}$} & $\geq 29$ & $\geq 47$ \\
\hline Prudence & & $\geq 19$ & $\geq 26$ \\
\hline Excitable & & $\leq 90$ & $\leq 85$ \\
\hline Imaginative & & $\leq 85$ & $\leq 75$ \\
\hline Skeptical & & & $\leq 87$ \\
\hline Diligent & & & $\leq 85$ \\
\hline
\end{tabular}

Note. All cutoff scores reflect normative percentile ranks.

TABLE 4.

Scale-Based Profile for Innovation (Technical Competency)

\begin{tabular}{|l|c|c|c|}
\hline Scale & Low fit & Moderate fit & High fit \\
\hline Ambition & & $\geq 23$ & $\geq 37$ \\
\hline Inquisitive & \multirow{3}{*}{$\begin{array}{c}\text { Fails to Satisfy } \\
\text { Moderate Fit } \\
\text { Minimum Scores }\end{array}$} & $\geq 24$ & $\leq 31$ \\
\cline { 1 - 1 } Excitable & & $\leq 90$ & $\leq 85$ \\
\hline Imaginative & & $\leq 85$ & $\leq 85$ \\
\hline Skeptical & & & $\leq 86$ \\
\hline Cautious & & & $\leq 8$ \\
\hline
\end{tabular}

Note. All cutoff scores reflect normative percentile ranks.

TABLE 5.

Scale-Based Profile for Strategic Planning (Leadership Competency)

\begin{tabular}{|l|c|c|c|}
\hline Scale & Low fit & Moderate fit & High fit \\
\hline Ambition & & $\geq 19$ & $\geq 23$ \\
\hline Learning Approach & \multirow{2}{*}{$\begin{array}{c}\text { Fails to Satisfy } \\
\text { Moderate Fit } \\
\text { Minimum Scores }\end{array}$} & $\geq 06$ & $\geq 10$ \\
\cline { 1 - 1 } Diligent & & $\leq 85$ & $\leq 69$ \\
\cline { 1 - 1 } Skeptical & & & $\leq 53$ \\
\hline Cautious & & & $\leq 70$ \\
\hline
\end{tabular}

Note. All cutoff scores reflect normative percentile ranks. 
enced in Tables 2 through 5. Each algorithm uses a combination of predictive scales from the HPI and HDS.

- Achievement Orientation $=($ Ambition + Prudence $+(100-$ Skeptical $)+(100-$ Cautious $)+(100-$ Imaginative) $) / 5$

- Building Relationships $=($ Interpersonal Sensitivity + Prudence $+(100-$ Excitable $)+(100-$ Skeptical $)+(100-$ Reserved) $) / 5$

- Innovation $=($ Ambition + Inquisitive $+(100-$ Skeptical $)+(100$ - Cautious $)+$ Imaginative $) / 5$

- Strategic Planning $=($ Ambition + Inquisitive + Learning Approach $+(100$ - Skeptical $)+(100$ - Diligent) $) / 5$

Benefits of using scale-based algorithms include balancing predictive validity and ease of interpretation by using interpretive scale scores in an algorithm. Like

subscale-based algorithms, scale-based algorithms are also flexible and compensatory in that individuals can make up for having a deficient score on one scale by having a more ideal score on a different scale included in the algorithm. Finally, this approach is flexible in that it can include a mix of scales across assessments without the limitation of mixing scales and subscales.

However, along these lines, it may be necessary to include scales from more than one assessment when predicting more than a few competencies to ensure sufficient differentiation and minimize overlap of predictor scales across competencies. As with subscale-based algorithms, using continuous algorithm scores instead of categorical low, moderate, or high levels of profile fit makes scale-based algorithms somewhat more difficult to interpret and less informative of needed feedback and coaching efforts than scale-based profiles.

\section{Procedures}

To investigate the consistency of scores across the three competency-based research solutions previously described, we scored scale-based profiles, subscale-based algorithms, and scale-based algorithms for each of the four competencies using the archival HPI and HDS dataset previously described. We then correlated competency scores across methods to determine how consistent the scores are across research solutions. These correlations allow us to examine Hypotheses $1 \mathrm{a}$ and $1 \mathrm{~b}$.

However, the more critical question concerns how well each scoring solution predicts performance. Because researchers commonly evaluate predictive validity by correlating predictor scores to job performance ratings, this requires complete datasets including scores on both predictors and outcome variables. As such, to examine the predictive validity of these competency-based scoring solutions, we followed recommendations by Johnson, Carter, and Tippins (2001) and developed correlation matrices between scale components (i.e., HPI subscales and scales, HDS scales) and performance ratings for each competency across multiple studies in a global research archive (Hogan Assessment Systems, 2016). These matrices allow us to examine relationships between predictors and competency-based performance ratings.

To determine the impact of competency scores across scoring methods on competency-based performance ratings, we sought to obtain data from studies that met four criteria. Specifically, studies had to (a) include both HPI and HDS data as predictors, (b) use a concurrent or predictive validation strategy with working adults, (c) include supervisor ratings of aligned competency-based performance outcomes, and (d) include basic demographic and occupational data about the study. We obtained these data from the global research archive previously described, identifying 17 independent studies $(\mathrm{N}=1,858)$ that met all of our criteria. We also conducted online searches to attempt to identify additional samples using three databases: PsycINFO, SocINDEX, and Business Source Complete (Carroll, 2007). We used "HPI," "Hogan Personality Inventory," "HDS," and "Hogan Development Survey" as our keyword search terms but did not find any additional studies not already included in the global research archive. All studies excluded from our analyses either did not include both the HPI and HDS as predictor measures or did not include performance outcomes aligned with competencies included in our research.

The 17 studies included in our analyses originally took place from 2004 to 2010 and include data from managerial, executive, sales, customer support, and service and support jobs in both the public and private sectors. These studies contain data from 13 different companies across seven industries including law and law enforcement, telecommunications, pharmaceuticals, construction materials and services, retail, healthcare, and automotive. Across studies, participants who reported demographic data were $70 \%$ male and $30 \%$ female with an average age of 39.35 years $(\mathrm{SD}=$ 10.19 years). Most of these participants were White (74\%), with Hispanic/Latino (9\%), Black/African-American (6\%), Asian (4\%), and two or more races $(2 \%)$ representing other $\mathrm{racial} / \mathrm{ethnic}$ groups.

We obtained correlations between HPI subscales, HPI scales, and HDS scales from a global normative dataset (Hogan Assessment System, 2011) and derived meta-analytic correlations between competency-based performance ratings and HPI subscales, HPI scales, and HDS scales from the archival criterion studies described above. We followed meta-analysis procedures outlined by Hunter and Schmidt (2004), using zero-order product-moment correlations (r) as effect sizes for all studies, a random-effects model allowing the population parameter to vary across studies, and one criterion measure per study to represent each competency.

To examine the relationship between competency scoring solutions and aligned performance ratings, we followed the unit-weighting procedure recommended by Johnson, 
Carter, Davison, and Oliver (2001). This procedure is based on an equation provided by Nunnally (1978) that calculates an estimate of the overall relationship from multiple predictors when each is unit weighted:

$$
r_{y x_{c}}=\frac{\overline{r_{y x_{i}}}}{\sqrt{\overline{r_{x x}}}}
$$

Where:

$\mathrm{ryx}_{\mathrm{c}}=$ the correlation of a unit-weighted sum of standardized scores $\mathrm{x}_{\mathrm{i}}$, with a variable $\mathrm{y}$

$\overline{\mathrm{ryx}_{\mathrm{i}}}=$ the mean correlation between a variable $\mathrm{y}$ and all scores $\mathrm{x}_{\mathrm{i}}$ making up the composite

$\overline{r_{x x}}=$ the mean of all elements in the $\mathrm{R}_{\mathrm{xx}}$ intercorrelation matrix

We corrected for criterion unreliability in supervisor ratings using the mean interrater reliability coefficient of .52 proposed by Viswesvaran, Ones, and Schmidt (1996). Although some (e.g., Mount \& Barrick, 1995; Ones, Viswesvaran, \& Schmidt, 1993) argue that predictor unreliability can also be corrected, we believe it is premature to estimate the validity of perfect constructs when there is no agreement regarding what they are. These calculations estimate the operational validities of our competency-based research solutions and allow us to examine Hypothesis 2.

\section{RESULTS}

Tables 6 through 9 present correlations summarizing the consistency of scores for each competency across scoring methods. Across competencies, scores from subscalebased algorithms and scale-based algorithms show an average correlation of .72. This association is the strongest relationship between scoring solutions, reflecting consistency in the scales included and the continuous scoring methods used to score each subscale or scale. Moreover, these correlations are higher than those between scale-based profiles and subscale-based algorithms or for scale-based profiles and scale-based algorithms for all four competencies examined.

Scores from scale-based profiles and scale-based algorithms show an average correlation of .57 across competencies. As expected, many of the same personality dimensions appear in profile and algorithm solutions for each competency, though the scoring method for each scale varies across research solutions. In addition, these correlations were higher than those between scale-based profiles and subscale-based algorithms for three of the four competencies examined.

Finally, scores from scale-based profiles and subscalebased algorithms show an average correlation of .53 across competencies. This is the lowest average correlation between methods across the four competencies examined.
Moreover, these correlations were lower than those between scale-based profiles and scale-based algorithms or those between subscale-based algorithms and scale-based algorithms for three of the four competencies examined. Taken together, these results provide support for Hypothesis 1 .

Along the diagonals in Tables 6 through 9, we also present observed and operational validity estimates for each competency based on analyses using the Nunnally (1978) equation. Results suggest that each research solution produces scores related to performance ratings for each competency. However, average validities indicate that predictive validities are similar for subscale- and scale-based algorithms, and higher for algorithm-based solutions than for profile-based solutions. Specifically, for two of the four competencies examined, subscale-based algorithms predict competency-based performance ratings better than scalebased algorithms or scale-based profiles. However, for the remaining two competencies and for the average validity across the four competencies, scale-based algorithms predict competency ratings better than subscale-based algorithms or scale-based profiles. As such, we find only partial support for Hypothesis 2. Overall, these results support the validity of competency-based research solutions, particularly subscale- or scale-based algorithms, in predicting competency-based performance.

\section{DISCUSSION}

Given the fact that subscale-based algorithms provide more detailed information than scale-based profiles and scale-based algorithms, we expected a larger advantage in predicting performance using this method. For two of our performance competencies (i.e., Innovation and Strategic Planning), subscale-based algorithms did perform better than our other methods. However, for the remaining two performance competencies (i.e., achievement orientation and building relationships), scale-based algorithms predicted performance more strongly than subscale-based algorithms. Multiple factors may explain these observed results.

One possibility relates to the bandwidth-fidelity dilemma (Cronbach \& Gleser, 1965) describing gains and losses in prediction based on using broad versus narrow personality constructs. Some researchers (Ones \& Viswesvaran, 1996; Salgado, 2003) advocate for using broad personality scales rather than narrow facets to predict behavior, whereas others (Hogan \& Roberts, 1996; Paunonen, 1998) argue that narrow constructs account for specific variance lost when using broad scales to predict performance. As such, outcomes like achievement orientation and building relationships may represent broader performance variables than other outcomes such as innovation and strategic planning, and our observed differences in prediction may result 
This model organizes performance competencies into four domains: (a) intrapersonal skills related to selfmanagement, (b) interpersonal skills concerning positive social relationships, (c) leadership skills related to building and maintaining effective teams, and (d) technical skills concerning mastery of business issues. In this model, the domains form a hierarchy of trainability where the earlier domains are harder to train and the later domains are more easily mastered through training. Returning to our findings, achievement orientation and building relationships reflect intrapersonal and interpersonal domains, respectively, whereas innovation and strategic planning represent technical and leadership domains. As such, it is possible that scale-based algorithms best predict intrapersonal and interpersonal outcomes that are difficult to train, whereas subscale-based algorithms best predict technical and leadership outcomes where narrow facets of personality align with specific behaviors acquired in training.

TABLE 6 .

Correlations Between Scoring Methods and Validities for Achievement Orientation

\begin{tabular}{|l|c|c|c|}
\hline & 1 & 2 & 3 \\
\hline 1. Scale-based profile & $.11(.15)$ & & \\
\hline 2. Subscale-based algorithm & $.51^{* *}$ & $.22(.31)$ & \\
\hline 3. Scale-based algorithm & $.55^{* *}$ & $.73^{* *}$ & $23(.32)$ \\
\hline
\end{tabular}

Note. $\mathrm{k}=17 ; \mathrm{N}=1,822 ; * *$ Correlation is significant at .01 level; Information in diagonal presents observed validity and operational validity after correcting for criterion unreliability (in parentheses).

TABLE 7.

Correlations Between Scoring Methods and Validities for Building Relationships

\begin{tabular}{|l|c|c|c|}
\hline & 1 & 2 & 3 \\
\hline 1. Scale-based profile & $.16(.22)$ & & \\
\hline 2. Subscale-based algorithm & $.58^{* *}$ & $.16(.22)$ & $.78^{* *}$ \\
\hline 3. Scale-based algorithm & $.65^{* *}$ & $.23(.32)$ \\
\hline
\end{tabular}

Note. $\mathrm{k}=17 ; \mathrm{N}=1,818 ; * *$ Correlation is significant at .01 level; Information in diagonal presents observed validity and operational validity after correcting for criterion unreliability (in parentheses).

TABLE 8.

Correlations Between Scoring Methods and Validities for Innovation

\begin{tabular}{|l|c|c|c|}
\hline & 1 & 2 & 3 \\
\hline 1. Scale-based profile & $.15(.21)$ & & \\
\hline 2. Subscale-based algorithm & $.57^{* *}$ & $.28(.39)$ & $.25(.35)$ \\
\hline 3. Scale-based algorithm & $.53^{* *}$ & $.83^{* *}$ & \\
\hline
\end{tabular}

Note. $\mathrm{k}=17 ; \mathrm{N}=1,823 ; * *$ Correlation is significant at .01 level; Information in diagonal presents observed validity and operational validity after correcting for criterion unreliability (in parentheses).

TABLE 9 .

Correlations Between Scoring Methods and Validities for Strategic Planning

\begin{tabular}{|l|c|c|c|}
\hline & 1 & 2 & 3 \\
\hline 1. Scale-based profile & $.12(.17)$ & & \\
\hline 2. Subscale-based algorithm & $.47^{* *}$ & $.25(.35)$ & \\
\hline 3. Scale-based algorithm & $.53^{* *}$ & $.54^{* *}$ & $.22(.31)$ \\
\hline
\end{tabular}

Note. $\mathrm{k}=17 ; \mathrm{N}=1,825 ; * *$ Correlation is significant at .01 level; Information in diagonal presents observed validity and operational validity after correcting for criterion unreliability (in parentheses). 
from those factors.

A related issue concerns the domain model of organizational performance first proposed by Warrenfeltz (1995).

Finally, our mixed support for Hypothesis 2 may arise from specific methodological issues in our research. It is possible that our results may reflect model overfitting and that the use of subscales may capitalize on chance in the data. It is also possible that our results reflect some unique element in our study samples. As such, we encourage future researchers to investigate this issue with other predictors and criterion outcomes to ensure the generalizability of results.

These observations notwithstanding, having multiple competency-based scoring solutions provides practitioners and academic researchers with flexibility in delivering customized competency information in a variety of solutions. In organizational use, this information proves useful across HRM applications, including applicant selection, employee development, HIPO identification, succession planning, and other administrative initiatives.

Because researchers can predict competency-based performance with scale-based profiles, subscale-based algorithms, or scale-based algorithms, a logical question concerns which approach is best. The answer largely depends on what information is needed about each competency and which method best captures Campion et al.'s (2011) best practices in a given context. For example, if an organization wants to provide interpretive feedback to help employees develop key capabilities, a profile solution may work best because that solution most naturally links to business objectives and can apply the same development model across organizational functions, departments, or job families. However, if organizations are only interested in maximizing prediction and are not concerned about interpreting scores, subscale- or scale-based algorithms may work best because those solutions best distinguish between top performers and average or poor performers. As a third example, if organizations are interested in both prediction and interpretation, we recommend using scale-based algorithms because that solution distinguishes between performance levels and can facilitate alignment of HRM interventions based on interpretive results.

Regardless of the chosen scoring solution, there are several benefits to using competency-based research solutions. First, organizations can use their competency model as the foundation for such efforts; this integrates the power of predictive assessments with the organization's own competency language, increasing relevancy and stakeholder buy-in. Second, competency methodologies can benefit from robust scientific models and evidence from archived criterion studies; these approaches can also be used with local validation studies to increase precision. Finally, competency solutions are user friendly, offering flexibility and ease of understanding. For example, such solutions could populate additional interview questions to probe areas of concern around specific competencies.

However, there are some other issues to also consider when implementing competency-based research solutions. First, competency-based solutions are most beneficial when users prefer to apply the language of an existing competency model. Although researchers can align predictor tools to any competency model, other providers can also step in and work behind the scenes within an organization's competency framework. Second, research investments for competency-based solutions are typically reasonable, but significant costs may be involved in developing and delivering customized competency-based solutions that use an organization's specific competency language. This is especially true for multinational corporations that may require such solutions across multiple languages. Finally, emerging off-the-shelf competency solutions may alleviate the problem of high costs associated with development and delivery by offering research-based systems for users to create their own competency-based deliverables.

The continuously growing use of competency models in organizations requires research solutions that are not only predictive but also flexible and customized. By offering a range of competency-based research solutions, I-O professionals can meet these challenges by providing accurate, interpretable information in a customized report tailored to the organization's own competency framework.

\section{REFERENCES}

Bartram, D. (2005). The Great Eight competencies: A criterioncentric approach to validation. Journal of Applied Psychology, 90, 1185-1203.

Campion, M. A., Fink, A. A., Ruggeberg, B. J., Carr, L., Phillips, G. M., \& Odman, R. B. (2011). Doing competencies well: Best practices in competency modeling. Personnel Psychology, 64, 225-262.

Carroll, J. (2007). EBSCO Publishing. Serials Review, 33, 145-148.

Cronbach, L. J., \& Gleser, G. G. (1965). Psychological tests and personnel decisions (2nd ed.). Urbana, IL: University of IIlinois Press.

Cucina, J. M., Vasilopoulos, N. L., \& Sehgal, K. G. (2005). Personality-based job analysis and the self-serving bias. Journal of Business and Psychology, 20, 275-290.

Digman, J. M. (1990). Personality structure: Emergence of the five-factor model. Annual Review of Psychology, 41, 417440.

Foster, J. L., Gaddis, B. H., \& Hogan, J. (2012). Personality-based job analysis. In M. A. Wilson, W. Bennett, Jr., S. G. Gibson, \& G. M. Alliger (Eds.), Handbook of work analysis (pp. 247-264). New York, NY: Taylor \& Francis.

Goldberg, L. R. (1992). The development of markers of the BigFive factor structure. Psychological Assessment, 4, 26-42. 
Guion, R. M. (1992, April). Matching position requirements and personality traits. Paper presented at the 7th Annual Conference of the Society for Industrial and Organizational Psychology, Montreal, Canada.

Highhouse, S., Zickar, M. J., Brooks, M. E., Reeve, C. L., SarkarBarney, S. T., \& Guion, R. M. (2016). A public-domain personality item bank for use with the Raymark, Schmit, and Guion (1997) PPRF. Personnel Assessment and Decisions, 2, 48-56.

Hogan Assessment Systems. (2011). Hogan Personality Inventory, Hogan Development Survey, \& Motives, Values, Preferences Inventory global norms: Documentation of normative data. Tulsa, OK: Author.

Hogan Assessment Systems. (2016). White paper: Hogan archive. Tulsa, OK: Hogan Research Division.

Hogan, J., \& Roberts, B. W. (1996). Issues and non-issues in the fidelity-bandwidth trade-off. Journal of Organizational Behavior, 17, 627-637.

Hogan, R., \& Hogan, J. (2007). Hogan Personality Inventory manual (3rd ed.). Tulsa, OK: Hogan Assessment Systems.

Hogan, R., \& Hogan, J. (2009). Hogan Development Survey manual (2nd ed.). Tulsa, OK: Hogan Press.

Horney, K. (1950). Neurosis and human growth. New York, NY: Norton.

Hunter, J. E., \& Schmidt, F. L. (2004). Methods of meta-analysis: Correcting error and bias in research findings. Newbury Park, CA: Sage Publications.

John, O. P. (1990). The "Big-Five" factor taxonomy: Dimensions of personality in the natural language and in questionnaires. In L. A. Pervin (Ed.), Handbook of personality theory and research (pp. 66-100). New York, NY: Guilford.

Johnson, J. W., Carter, G. W., Davison, H. K., \& Oliver, D. H. (2001). A synthetic validity approach to testing differential prediction hypotheses. Journal of Applied Psychology, 86, 774780.

Johnson, J. W., Carter, G. W., \& Tippins, N. T. (2001, April). A synthetic validity approach to the development of a selection system for multiple job families. Paper presented at the 16th Annual Conference of the Society for Industrial and Organizational Psychology, San Diego, CA.

McCrae, R. R., \& Costa, P. T., Jr. (1987). Validation of the five-factor model of personality across instruments and observers. Journal of Personality and Social Psychology, 52, 81-90.

Mount, M. K., \& Barrick, M. R. (1995). The Big Five personality dimensions: Implications for research and practice in human resources management. In G. R. Ferris (Ed.), Research in personnel and human resources management (Vol. 13, pp. 153-200). Greenwich, CT: JAI Press.

Nunnally, J. C. (1978). Psychometric theory (2nd ed.). New York, NY: McGraw-Hill.

Ones, D. S., \& Viswesvaran, C. (1996). Bandwidth-fidelity dilemma in personality measurement for personnel selection. Journal of Organizational Behavior, 17, 609-626.

Ones, D. S., Viswesvaran, C., \& Schmidt, F. L. (1993). Comprehensive meta-analysis of integrity test validation: Findings and implications for personnel selection and theories of job performance. Journal of Applied Psychology, 78, 679-703.
Paunonen, S. V. (1998). Hierarchical organization of personality and prediction of behavior. Journal of Personality and Social Psychology, 74, 538-556.

Raymark, P. H., Schmit, M. J., \& Guion, R. M. (1997). Identifying potentially useful personality constructs for employee selection. Personnel Psychology, 50, 723-736.

Rodriguez, D., Patel, R., Bright, A., Gregory, D., \& Gowing, M. K. (2002). Developing competency models to promote integrated human resource practices. Human Resource Management, 41, 309-324.

Salgado, J. F. (2003). Predicting job performance using FFM and non-FFM personality measures. Journal of Occupational and Organizational Psychology, 76, 323-346.

Sanchez, J. I., \& Levine, E. L. (2009). What is (or should be) the difference between competency modeling and traditional job analysis? Human Resource Management Review, 19, 53-63.

Schippmann, J. S. (2010). Competencies, job analysis, and the next generation of modeling. In J. C. Scott \& D. H. Reynolds (Eds.), Handbook of workplace assessment (pp. 197-231). San Francisco, CA: John Wiley \& Sons.

Schippmann, J. S., Ash, R. A., Battista, M., Carr, L., Eyde, L. D., Hesketh, B., Kehroe, J.....Sanchez, J. I. (2000). The practice of competency modeling. Personnel Psychology, 53, 703-740.

SHL Group Ltd. (2006). OPQ32 technical manual. Thames Ditton, Surrey, UK: Author.

Sliter, K. A. (2015). Assessing 21st century skills: Competency modeling to the rescue. Industrial and Organizational Psychology: Perspectives on Science and Practice, 8, 284-289.

Tett, R. P., \& Burnett, D. D. (2003). A personality trait-based interactionist model of job performance. Journal of Applied Psychology, 88, 500-517.

Tett, R. P., \& Guterman, H. A. (2000). Situation trait relevance, trait expression, and cross-situational consistency: Testing a principle of trait activation. Journal of Research in Personality, 34, 397-423.

Viswesvaran, C., Ones, D. E., \& Schmidt, F. L. (1996). Comparative analysis of the reliability of job performance ratings. Journal of Applied Psychology, 81, 557-574.

Warrenfeltz, R. B. (1995, April). An executive-level validation of the Borman and Brush taxonomy. Paper presented at the 10th Annual Conference of the Society for Industrial and Organizational Psychology, Orlando, FL.

RECEIVED 08/04/16 ACCEPTED 10/11/17 